\title{
Gamma Prima Phase Coalescence in Nickel Base Alloys
}

Peretti, M. and Versaci, R.A.

Departamento Materiales, Centro Atómico Constituyentes, Comisión Nacional de Energía Atómica, Avda. Del Libertador 8250, C1429BNP, Buenos Aires, Argentina.

In two phase alloy systems it has become common practice to apply the theoretical analysis due to Lifshitz and Slyosov [1] and Wagner [2] to the experimental data. The Lifshitz-Slyosov-Wagner (LSW) theory predicts the mean linear dimension of the precipitate particles to increase by the cube root of the time. The LSW theory is strictly applicable only when the volume fraction of precipitate tends to zero.

In the nickel base alloys, as the INCONEL 713C, the fraction in volume of the precipitate phase $\gamma^{\prime}$ it is of the order of $70 \%$. Under these conditions the theory LSW is not applicable, therefore in this work the coalescence of the particles is analysed. For it is studied it the evolution of the radius in function of the time in the INCONEL 713C alloy. Heat treatment solubilized 2 hours at $1176{ }^{\circ} \mathrm{C}$, precipitation at $925{ }^{\circ} \mathrm{C}$ during 16 hours. Specimen were afterwards aged in argon atmosphere at $950{ }^{\circ} \mathrm{C}$ for different times, between 0 and 23865 hours, and then quenched.

The figure 1 shows the characteristics of the $\gamma^{\prime}$ phase previous to the thermal treatment and in the figures 2 the growth directional of the phases $\gamma^{\prime}$ in the direction $<100>$. Figure 3 show the coalescence of the particles and the figures 4 again the coalescence of the particles of the $\gamma^{\prime}$ phases. In the graph 5 the variation of the radius is observed with the thermal treatments, this radius acquires a maximum for a treatment of 2380 hours at $950{ }^{\circ} \mathrm{C}$.

This fluctuation of the radius cannot be explained by the theory LSW that adjusts for to law of $\mathrm{t}^{1 / 3}$ until the maximum at the 1000 hours, the growth of the radius until reaching the maximum at 2380 hours can be explained by means of the coalescence of the particles $\gamma^{\prime}$, this is observed clearly in the figure 3, just as it proposes by Davies et al. [3]. An analytic form of explaining this is to think that what modifies the speed of growth just as it proposes it in its model Ges et al.[4], but from the figures is clear the coalescence of $\gamma^{\prime}$ particles.

The radius changes when it arrives to the maximum of the value of the radius, the field of tensions takes to a separation of the particles, what explains a decrease in the value of the radius, this particles grow and coalesce again increasing the value of the radius.

These changes in the radius are accompanied by modifications in the morphology of the particles and with modifications in the stress fields in the matrix, these change mechanical properties of material at high temperature.

\section{References}

[1] I.M. Lifshitz and V.V. Slyosov, J. Phys. Chem. Solids 19, (1961), 35.

[2] C. Wagner, Z. Electrochem. 65, (1961), 581.

[3] C.K.L. Davies et. al., Acta Metallurgica, 28, (1980), 179.

[4] A. Ges et al., J. Mater. Sci. 32, (1997), 3687. 


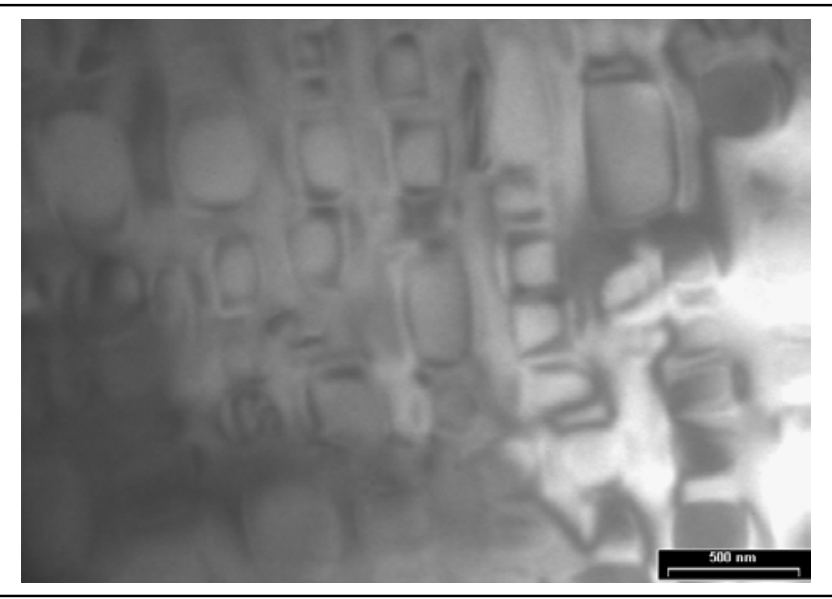

Fig. 1. Treated 120 hours at $950^{\circ} \mathrm{C}$.

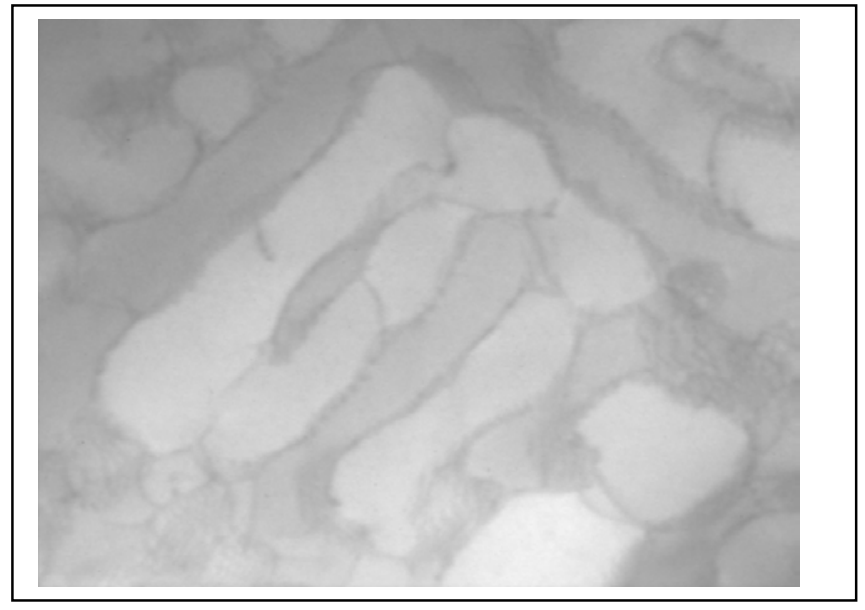

Fig. 3. Treated 2380 hours at $950^{\circ} \mathrm{C}$.

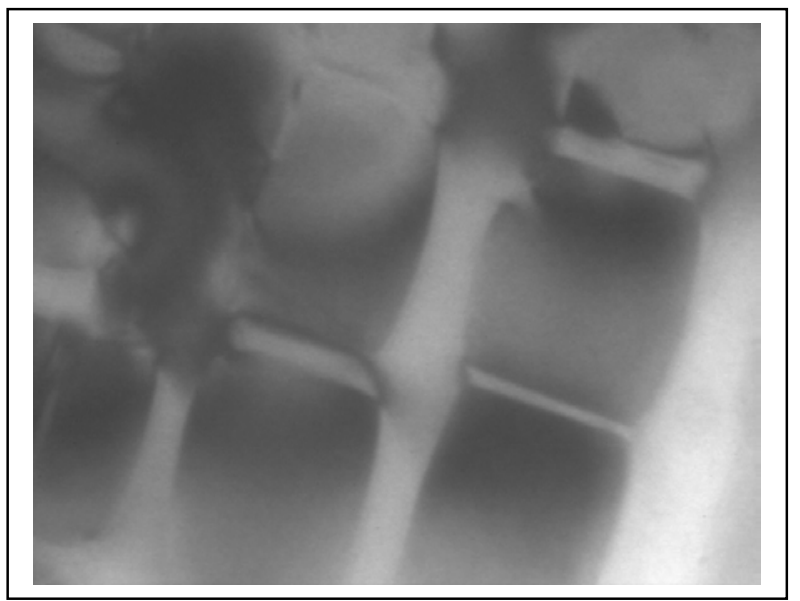

Fig. 2. Treated 1125 hours at $950^{\circ} \mathrm{C}$

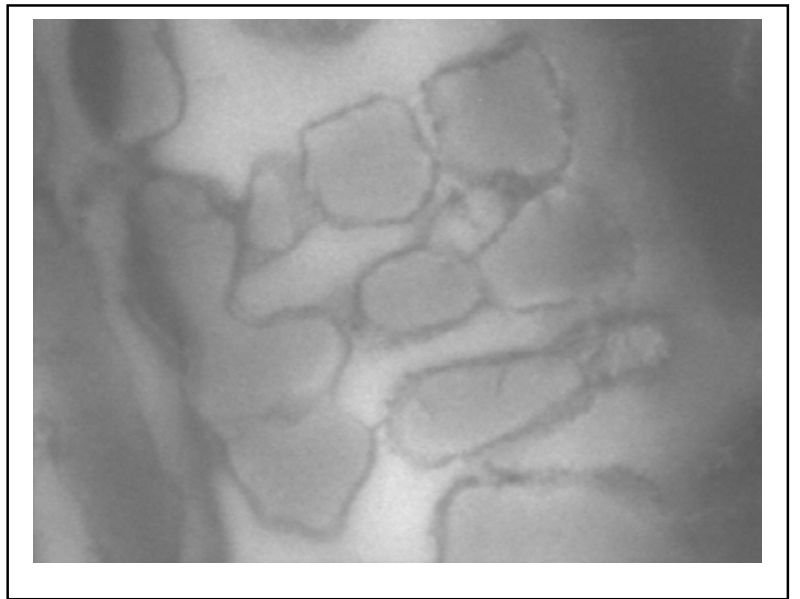

Fig. 4. Treated 15705 hours at $950{ }^{\circ} \mathrm{C}$

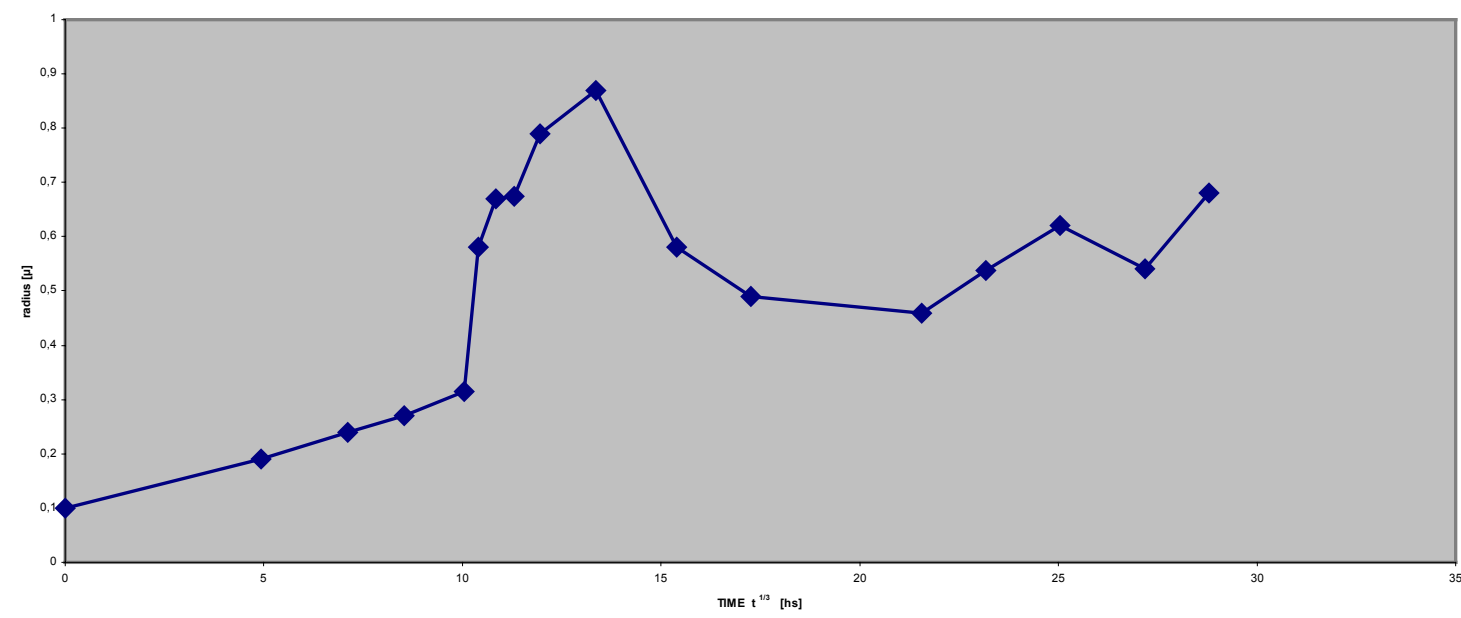

Figure 5. 